\title{
Detection of Cysticercosis in Palpable Subcutaneous and Intramuscular Nodules in FNAC - A Chance Diagnosis - A Study of 15 Cases
}

\author{
Anuradha De Pati ${ }^{1}$, Selim Akhtar² \\ ${ }^{1}$ Department of Pathology, School of Tropical Medicine, Kolkata, West Bengal, India. 2Department of \\ Obstetrics and Gynaecology, Calcutta National Medical College and Hospital, Kolkata, West Bengal, India.
}

\section{ABSTRACT}

\section{BACKGROUND}

Cysticercosis is caused by a parasitic tissue infection caused by encysted larval form of tape worm Taenia solium and usually presents as painless subcutaneous or intramuscular nodules of long duration. It is quite a common disease worldwide, but the actual incidence is often underestimated. Fine needle aspiration cytology plays an important role in quick and easy detection of cysticercosis especially in easily approachable sites like superficial palpable lesions. We wanted to study the important role of FNAC in unusual diagnosis of cysticercosis in superficial palpable swelling.

\section{METHODS}

In this case series of 15 cases of palpable nodular lesions at different sites, clinically diagnosed as lipoma, neurofibroma, inclusion cyst or lymphadenopathy in majority of cases, except one which was clinically and radiologically suspected as parasitic cyst were included. Cytomorphological features were analysed on FNAC smears and subsequent biopsy was done wherever possible.

\section{RESULTS}

In this study, out of 15 cases, majority of the patients were in the age group of 20 - 30 years. Mean age is 23.93 years with a standard deviation of 11.17 . Among them, 10 were male (66.6\%) and 5 were female $(33.3 \%)$. The most common sites were upper and lower extremities, followed by head and neck, and then abdominal wall. Most of the cases were clinically misdiagnosed as lymphadenitis, lipoma, neurofibroma, inclusion cyst or soft tissue tumour. Definitive diagnosis could be made on FNAC by recognition of parasitic fragments in nine cases (60\%). In rest 6 cases (40\%), larval fragments could not be identified on cytology smears and diagnosis of parasitic infection was suggested on the basis of nature of aspirate as clear fluid, eosinophils infiltration, palisaded histiocytes, foreign body giant cells, epithelioid cells, and dirty granular background. Histopathological correlation was available in 4 cases.

\section{CONCLUSIONS}

Subcutaneous cysticercosis can be diagnosed by FNAC which is a low cost safe outpatient procedure. The cytological diagnosis is straight forward in cases where parasitic structure is identified in cytology smears. In other cases, presence of eosinophils, palisaded histiocytes, typical granular dirty background always give a clue to the pathologist to become suspicious for cysticercosis. Cysticercosis should always be kept in mind as a differential diagnosis in all kinds of subcutaneous swellings in endemic areas.

\section{KEY WORDS}

Cysticercosis, FNAC, Parasite, Differential Diagnosis

\author{
Corresponding Author: \\ Dr. Selim Akhtar, \\ Neel Diganta Enclave, Flat No. I-3, \\ $3^{\text {rd }}$ Floor, Block-B, Sethpukur, \\ P.O. + P. S. Barasat, North 24 \\ Parganas-700124, West Bengal, India. \\ E-mail:s.akhtar19841984@gmail.com
}

DOI: $10.14260 / \mathrm{jemds} / 2020 / 446$

How to Cite This Article:

Pati AD, Akhtar S. Detection of cysticercosis in palpable subcutaneous and intramuscular nodules in FNAC- a chance diagnosis- a study of 15 cases. J. Evolution Med. Dent. Sci. 2020;9(29):2049-2052, DOI: 10.14260/jemds/2020/446

Submission 10-04-2020,

Peer Review 10-06-2020,

Acceptance 16-06-2020,

Published 20-07-2020.

Copyright (c) 2020 JEMDS. This is an open access article distributed under Creative Commons Attribution License [Attribution 4.0 International (CC BY 4.0)] 


\section{BACKGROUND}

Man occasionally serves as larval host (incidental or accidental) of pork tape worm Taenia solium. Human is infected either by drinking water or by eating uncooked vegetables infected with eggs. ${ }^{1}$ It is endemic in Mexico, central and South America, Africa, and Asia where humans live in close contact with pigs. In India it is found commonly in northern parts of the country and common manifestation of human cysticercosis is a single or more than one subcutaneous or intramuscular nodule which is usually clinically misdiagnosed as lipoma, enlarged lymph node, neurofibroma, inclusion cyst etc. The prevalence of cysticercosis in India ranges somewhere between $7-26 \%$. Since cysticercosis presents mostly as superficial palpable swelling they can be easily approachable for FNAC, a rapid minimally invasive tool for diagnosis. ${ }^{2}$ Early diagnosis of such lesions also leads to a good outcome as they are highly responsive to specific antimicrobial therapy. The diagnostic role of FNAC in cysticercosis was first emphasized by Kung et al. in $1989^{3}$. Currently other diagnostic modalities like radiological imaging, serology and immunologic detection are also done, but demonstration of larva remains the gold standard for definitive diagnosis. The diagnosis is further confirmed by histopathological examination by excision biopsy. Control measures include health education, adequate sewage treatment and disposal, proper cleaning and cooking of vegetables, meat inspection. Drug of choice is albendazole for 7 to 14 days, longer course (up to 28 days) may be required in some cases. Corticosteroids may be added to control inflammation.

\section{Objectives}

To highlight the role of FNAC in definitive diagnosis of cysticercosis is even in clinically unexpected cases with a spectrum of cytological details of entire range from viable cysts through inflammatory, necrotic and calcified lesions.

\section{METHODS}

We performed case series in Cytology section of department of pathology, in school of tropical medicine, Kolkata based on FNAC which is an outpatient procedure. Currently our Department carries out about 450 to 500 FNAC per year. In this case series over the period of 8 years from February 2011 to March 2019, the records of all those patients who were finally diagnosed as cysticercosis on FNAC were retrieved and 15 patients presented with palpable nodules at different sites (sample size taken as per convenience). Age, sex, site, size of lesion, nature of aspiration and clinical diagnosis were noted.

Fine needle aspiration was done with $23 \mathrm{G}$ needle and 10 $\mathrm{ml}$ disposable syringe. The nature of aspirate was noted and smeared on glass slides, in case of fluid smears were prepared after centrifugation. Smears were stained as per our routine procedure of the Department as follows: Air dried smear stained with MGG stain and Z-N stain (when sent as lymph node), alcohol fixed (95\% ethyl alcohol) smear with $\mathrm{H}$ \&E stain. Subsequent histopathological examination was evaluated whenever possible and findings were correlated with cytological diagnosis.

\section{Statistical Analysis}

The data was entered in Microsoft excel 2013. Percentages, Mean and Standard deviation as per necessity were calculated using statistical software STATA version 12 .

\section{RESULTS}

This study included 15 patients in the various age groups of 5 years to 53 years (mean age $=23.93$ years and standard deviation is 11.17). Majority of the patients were in the age group of 20-30 years. (Table-1).

\begin{tabular}{|cc|}
\hline Age in Years & Number of Patients (n=15) \\
5 years & 1 \\
9 years & 1 \\
18 years & 2 \\
21 years & 3 \\
23 years & 2 \\
25 years & 2 \\
31 years & 2 \\
35 years & 1 \\
53 years & 1 \\
\hline Table 1. Age Distribution of Patients $(\boldsymbol{n}=\mathbf{1 5})$, \\
Mean= 23.93 Years, Standard Deviation= 11.17
\end{tabular}

Among 15 patients 10 were male $(66.6 \%)$ and 5 were female (33.3\%). (Table 2) There was male preponderance.

\begin{tabular}{|cc|}
\hline Male & 10 \\
Female & 5 \\
\hline Table 2. Sex Distribution of Patients ( $\mathbf{n = 1 5 )}$ \\
\hline
\end{tabular}

Most common site of presentation were upper and lower extremities followed by head and neck then abdominal wall. (Table-3)

\begin{tabular}{|cc|}
\hline Site of Lesion & Number of Cases (n=15) \\
Upper extremity & $4(26.66 \%)$ \\
Lower extremity & $3(20 \%)$ \\
Abdominal wall & $2(13.33 \%)$ \\
Chest wall & $1(6.66 \%)$ \\
Back & $2(13.33 \%)$ \\
Cervical region & $2(13.33 \%)$ \\
Shoulder & $1(6.66 \%)$ \\
\hline Table 3. Affected Site Distribution \\
\hline
\end{tabular}

\begin{tabular}{|ccc|}
\hline Clinical & Cytology & $\begin{array}{c}\text { Number of } \\
\text { Patients (n=15) }\end{array}$ \\
Diagnosis & Bladder wall of cysticercosis & 3 \\
Neurofibroma & Cellular reaction & 1 \\
TB Lymph node & Bladder wall of cysticercosis & 3 \\
Lipoma & Cellular reaction with necrosis & 1 \\
Lymph adenitis & Known case of neurocysticercosis & 1 \\
? Parasitic cyst & Bladder wall of cysticercosis & 2 \\
Inclusion cyst & Cellular reaction with epithelioid cell & 3 \\
Soft tissue tumour & Table 4. Provisional Diagnosis and Cytological Findings \\
\hline
\end{tabular}

All the patients presented with slow growing nodular lesions soft to firm in consistency. Provisional diagnosis of parasitic lesion was made only in two cases with the help of USG. One of them was an anterior abdominal wall swelling and the other was a treated case with past history of neurocysticercosis who developed swelling in infrascapular region, whereas majority of the cases were clinically misdiagnosed as lipoma, neurofibroma, inclusion cyst, lymphadenitis or soft tissue tumour. (Table-4).

Clear fluid like material was aspirated in 11 cases and purulent material in rest of the cases. No complications occurred in any of the cases. 


\section{DISCUSSION}

Larval cysts of the tapeworm Taenia solium is responsible for cysticercosis, a parasitic tissue infection. It is an ancient disease in human and has even been detected in Egyptian mummies by paleoparasitologist. ${ }^{4}$ The word "Cysticercus" is derived from two Greek words, 'Kystis' meaning cyst and "Kertos" meaning tail due to its appearance. ${ }^{5}$

This disease is no doubt a public health problem in endemic countries. In India the northern part is more affected. It is now reported in developed countries too due to frequent migration and changes in travel patterns. It may infect brain, muscle, or other tissue and can be a major cause of adult onset seizure disorder in low-income countries. It is endemic in areas where people have poor sanitation and pigs roam freely and eat human faeces.

Cestodes have two stage life cycles besides the egg phaselarva and adult. Pig is an intermediate host and human is considered as definite host. Cysticercus cellulosae, the larval form of Taenia solium is the cause of cysticercosis. The adult form lives human intestine, attaches to the intestinal wall by a scolex. After that it sheds gravid proglottids. These are passed into the water or soil and the eggs are released. When an intermediate host consumes the eggs, oncospheres are released which burrow through the intestinal wall to reach various tissues of the host. There they develop into encysted cysticerci. When undercooked meat/contaminated vegetables are eaten, these cysticerci are released and they are attached with intestine of the definite host. There they develop into adult worm and thus the life cycle is completed.

Human get cysticercosis when they swallow eggs which are excreted in the stool of people having adult tapeworm. This may happen when people take water or food contaminated with tapeworm eggs. Human is infected with tapeworms (taeniasis) by eating undercooked infected pork.

The Cysticercus alter the host immune response, both cellular as well as humoral immunity by releasing certain substances locally (e.g., paramyosin, taenia statin).6,7 Gradually the inflammatory response leads to degeneration of the parasite, granuloma formation and calcification.

Cysticerci, can develop in the muscles, the eyes, the brain, and/or the spinal cord. Other commonly affected sites are subcutaneous tissue, heart, liver, lungs, peritoneum.

Symptoms of cysticercosis depend on the location, size, number, and stage of the cysts. Neurocysticercosis is the most serious risk of $\mathrm{T}$. solium infection which leads to space occupying of brain.

Soft tissue cysticercosis is caused by encysted larval form of tape worm Taenia solium and usually presented as painless subcutaneous or intramuscular nodules for long duration. Clinically, it is difficult to differentiate cysticerci from soft tissue lesions, lymphadenopathy, intramuscular nodules, subcutaneous cystic, or parasitic nodules. The similar clinical presentation is caused by other parasites like Multiceps and Spargana, Spirometra Mansonoides. Hydatid cyst caused by the larva of Echinococcus Granulosus can also occur in the subcutaneous tissue, but it is an unusual presentation. ${ }^{8}$ Cytomorphological features of the aspirate can differentiate each other. The suckers and hooklets are present in Cysticerci and coenuri while it is absent in Spargana. Multiple protoscolices are seen in Coenures while cysticerci has only one scolex, and it is rarely seen in cytological findings.

Diagnosis is usually done by histopathological examination. X-ray, CT scan, MRI may be helpful. Serological tests like ELISA, radioimmunoassay, Complement Fixation test can also be used.

FNAC diagnosis of Cysticercus cellulosae is unusual and the current study highlighted the role of cytology in diagnosis of cysticercosis.

In our study all fifteen cases were a chance diagnosis among the patients routinely referred to the Department of Pathology for FNAC of superficial palpable nodules from OPD of different disciplines. All the patients had painless subcutaneous swelling in extremities, trunk, back, abdomen clinically diagnosed as lipoma, neurofibroma, lymphadenopathy, inclusion cyst etc. Only in two cases cytological diagnosis was consistent with clinical diagnosis. One patient had a cystic swelling in anterior abdominal wall, and it was suspected to be a parasitic cyst in USG findings which showed a hypoechoic lesion without calcification. Another one was a treated case of neurocysticercosis who developed infrascapular swelling later.

Cysticercosis is more common than we usually thought of and FNAC plays an important role in quick diagnosis of the lesion where actual parasitic structure is identified. Cysticercus can affect any organ but especially common in skeletal muscle and subcutaneous tissue, eye and CNS. Aspiration of clear fluid and varying proportions of inflammatory cells (e.g. eosinophils, neutrophils, plasma cells, giant cells) in a palpable nodule has a high index of suspicion as that of parasitic origin even in the absence of identifiable parasitic fragments. Although in a significant number of cases, aspirate may also be purulent or haemorrhagic.

Fully developed cysticercosis is a milky white opalescent elongated to oval cystic structure about $1 \mathrm{~cm}$ in diameter. Cysts usually contain fluid and a single invaginated scolex having rostellum, four suckers and 22-32 small hooklets. Cyst wall is multi-layered $100-200 \mathrm{~mm}$ thick and covered with microvilli. Though scolex in cytological smear is very uncommon findings. ${ }^{9}$ None of our cases show scolex in FNA smears. Presence of cellular infiltrate composed of eosinophils, palisaded histiocytes, giant cells or granuloma usually alert the pathologist to search for parasitic fragments or suggest the diagnosis of parasitic infeststion. ${ }^{10}$

Diagnostic criteria for cysticercosis on FNAC smear is identification of parasitic fragments like bluish fibrillary structures sometimes with honey coming, teguments thrown into round wavy folds, scolex, hooklets and hyaline membrane surrounding it. Viable Cysticercus may not cause inflammatory response and show a clean acellular background. Background reactive cellular inflammatory components in varying proportions-lymphocytes, plasma cells, eosinophils, neutrophils, giant cell etc. usually seen when the parasite degenerate. There may be foreign body granuloma, necrosis and calcification which suggest parasitic cyst. Similar cytological findings were described in a study of 30 cases of cysticercosis by A Rajvanshi, S Radhika et al ${ }^{11}$.A study conducted by Lakhey $\mathrm{M}$ et al. on 43 cases of suspected cysticercosis, definitive evidence of cysticercosis was found in $72.09 \%$ cases and parasitic inflammation was suggested in $27.9 \%$ of cases. $^{12}$ 
Histopathological examination of surgically excised nodules is the most reliable and definite method of diagnosis. Serological test or radiological findings such as calcified cyst can be helpful also. Though FNAC is a reliable and costeffective procedure for diagnosis of subcutaneous cysticercosis, it obviates the need of subsequent histological examination, but the parasite may not be demonstrated even on biopsy examination and diagnosis can be suggested depending on the cellular reaction of the cyst wall. ${ }^{13}$

In endemic areas, cysticercosis should be considered as one of the differential diagnosis of the subcutaneous swelling. In a study of $\mathrm{R} C$ Adhikari et al. biopsy confirmation was possible in 5 cases out of total 10 cases. $^{14}$

In a developing country like India specially in regions of poverty and poor personal hygiene cytological diagnosis of cysticercosis in superficial palpable swelling at different sites by FNAC - a rapid, safe, reliable and procedure on an outpatient basis proves to be cost effective since it obviates the need for biopsy. ${ }^{15,16}$

It is potentially a dangerous systemic disease with variable clinical manifestations diagnosed radiologically and serologically but demonstration of parasitic larva in FNAC smear or histopathological section is still the gold standard. ${ }^{3}$

\section{CONCLUSIONS}

Subcutaneous cysticercosis can be diagnosed easily by FNAC which is a low cost, rapid, and safe outpatient procedure. The cytological diagnosis is straight forward in cases where parasitic structure is identified in smears. In other cases, presence of eosinophils, palisaded histiocytes, typical granular dirty background always alert pathologists to give a diagnosis of 'suspicious for cysticercosis'. Cysticercosis should always be kept as a differential diagnosis in all lesions of subcutaneous swellings in endemic areas specially in regions of poverty and poor personal hygiene.

\section{REFERENCES}

[1] Chatterjee KD. Parasitology and helminthology in relation to clinical medicine. $5^{\text {th }}$ edn. Calcutta: Chatterjee Medical Publishers 1980:116-32.
[2] Kala P, Khare P. Fine-needle aspiration cytology as a diagnostic modality for cysticercosis: a clinicocytological study of 137 cases. J Cytol 2014;31(2):68-72.

[3] Kung IT, Lee D, Yu HC. Soft tissue cysticercosis. Diagnosis by fine needle aspiration. Am J Clin Pathol 1989;92(6):834-5.

[4] Bruschi F, Masetti M, Locci MT, et al. Short report: cysticercosis in an Egyptian mummy of the late ptolemaic period. Am J Trop Med Hyg 2006;74(4):598-9.

[5] Bhandary S, Singh R, Karki P, et al. Cysticercosis of tongue-diagnostic dilemma. Pac Health Dialog 2004;11(1):87-8.

[6] Ash LR, Orihel TC. Atlas of human parasitology. $3^{\text {rd }}$ edn. Chicago: IL: American Society of Clinical Pathologists 1990:236-7.

[7] Kala P, Khare P. Fine needle aspiration cytology as a diagnostic modality for cysticercosis: a clinicocytological study of 137 cases. J Cytol 2014;31(2):68-72.

[8] Singh N, Arora VK, Bhatia A. Are all subcutaneous parasitic cysts cysticercosis? Acta Cytol 2006;50(1):1145.

[9] Bhardwaj S, Rather G. Fine needle aspiration cytology of ctsticercosis: a study of 30 cases. J Cytol 2019;36(1):1821.

[10] Gill M, Dua S, Gill PS, et al. Cytomorphological spectrum of subcutaneous and intramuscular cysticercosis: a study of 22 cases. J Cytol 2010;27(4):123-6.

[11] Rajwanshi A, Radhika S, Das A, et al. Fine needle aspiration cytology in the diagnosis of cysticercosis presenting as palpable nodules. Diagn Cytopathol 1991;7(5):517-9.

[12] Lakhey M, Hirachand S, Akhter J, et al. Cysticercoci in palpable nodules diagnosed in fine needle aspiration cytology. J Nepal Med Assoc 2009;48(176):314-7.

[13] Handa U, Garq S, Mohan H. Fine needle aspiration in diagnosis of subcutaneous cysticercosis. Diagn Cytopathol 2008;36(30:183-7.

[14] Adhikari RC, Aryal G, Jha A, et al. Diagnosis of subcutaneous cysticercosis in fine needle aspirations: a study of 10 cases. Nepal Med Coll J 2007;9(4):234-8.

[15] Kamal MM, Grover SV. Cytomorphology of subcutaneous cysticercosis. A report of 10 cases. Acta Cytol 1995;39(4):809-12.

[16] Verma K, Kapila K. Fine needle aspiration diagnosis of cysticercosis in soft tissue swellings. Acta Cytol 1989;33(5):663-6. 